An Interference Simulator for Quantitative Determination of the Susceptibility of Flame Detectors to False Alarm

A. Scheidweiler

Cerberus Company

Maennedorf, Switzerland

Translated for:

Center for Fire Research Institute for Applied Technology National Bureau of Standards

Washington, D. C. 20234

November 1975

Final Report

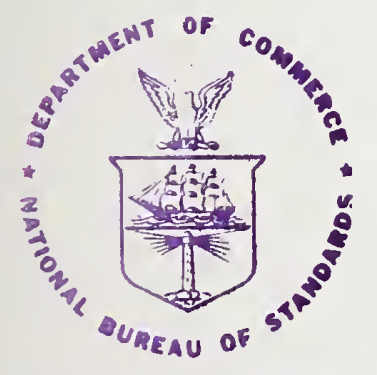

U S. DEPARTHENT OF COMMERCE

NATIONAL QUPEAU OF STANDAROS 



\section{AN INTERFERENCE SIMULATOR FOR QUANTITATIVE DETERMINATION OF THE SUSCEPTIBILITY OF FLAME DETECTORS TO FALSE ALARM}
A. Scheidweiler

Cerberus Company

Maennedorf, Switzerland

Translated for:

Center for Fire Research

Institute for Applied Technology

National Bureau of Standards

Washington, D. C. 20234

November 1975

Final Report

U.S. DEPARTMENT OF COMMERCE, Rogers C.B. Morton, Secretary James A. Baker, III, Under Secretary

Dr. Betsy Ancker-Johnson, Assistant Secretary for Science and Technology

NATIONAL BUREAU OF STANDARDS, Ernest Ambler, Acting Director 

This report is a translation of paper prepared by $A$. Scheidweiler and presented by him at the Seventh International Seminar on Problems in Automatic Fire Detection held in Aachen, Germany, on March 5-6, 1975. The Seminar was sponsored by the Institute for Electrical Communications Engineering in Aachen in conjunction with the Gesamthochschule in Duisberg.

This translation has been prepared to disseminate useful information to interested fire research personnel on a need-to-know basis and is not an original work of the Center for Fire Research.

We express our appreciation to the author, Dr. A. Scheidweiler for his permission and assistance in making this information available.

We also express our appreciation to Joint Publication Research Service, Arlington, Virginia, who provided the translation of the original paper. 

AN INTERFERENCE SIMULATOR FOR QUANTITATIVE DETERMINATION OF THE SUSCEPTIBILITY OF FLAME DETECTORS TO FALSE ALARM

\section{A. Scheidweiler}

All fire detectors are susceptible to false alarms, i.e., responding to fire-like conditions when no fire is present. Of all the known fire detectors, flame detectors are probably the most false alarm prone of any of the fire detectors, primarily because these detectors are subjected to more environmental influences resembling the detectors' operating mode than any other fire detector.

In this paper, the author describes an investigation into the susceptibility of flame detectors to false alarms. The author describes a test apparatus, constructed and used by his firm, to evaluate the susceptibility of currently-available flame detectors to false alarms. In addition, the apparatus can be used to evaluate prototype flame detectors.

The data developed indicates the false alarm susceptibility of each type of flame sensor. The data also provides a means of selecting a flame detector having the greatest resistance to known or predictable pseudo-fire sources.

Key words: False alarms; false alarm simulator; fire detection; fire detector; flame detection; flame detector. 
My paper has to do with a problem which relates in this paper only to flame detectors, although in general it plays an important role in the evaluation of fire detection devices. This discussion deals with the investigation of susceptibility to false alarm, where, however, we do not understand this to mean the occurrence of an alarm because of deficient engineering reliability but rather the deception of a detection device by interference factors which behave in a manner similar to the behavior of fire-indicating parameters.

You will certainly agree with the assertion that radiation detectors unquestionably belong among those fire detectors upon whose "intelligence" we impose the most exacting requirements. The fire parameter to which they respond, namely electromagnetic flame radiation, is more frequently simulated by environmental influences than in the case of any other type of detector. Just consider the effect of solar radiation, artificial light sources and even heating radiators. It is true that research and development have made significant progress in the area of these detectors - not least of all in fundamental and pioneering studies in this Institute -- yet no one disputes the fact that when radiation detectors are employed, even with the most careful planning, one must still reckon with an increased number of so-called deception alarms. This circumstance is all the more regretable since flame detectors could perform a very important function, particularly in the protection of property, as, for example, in the control of the triggering process for extinguishing installations. But it is precisely here, because of the associated consequences, that it is particularly desirable that false alarms be avoided. 
However, it is also justifiable to expect a fire detector to have high response sensitivity in order that countermeasures may be applied as early as possible. But, in experience, with increasing sensitivity there is also the increasing probability of a false alarm. Hence, it is a question of finding the right compromise here; i.e., expressed mathematically, the fire detector should exhibit a ratio of recognition probability to deception probability which is as large as possible. If in this way one defines a so-called "figure of merit" as a measure of quality then there at once arises the question as to how one can obtain quantitative statements about these probabilities. A mathematical calculation, initially, would presuppose setting up a catalog of all possible flame spectra and interference quantities with the associated probabilities of their occurrence. Unfortunately, at the present time such information is not yet available and it will probably be a long time, if ever, before it is available.

Parallel to this problem we have the steadily increasing need, even today, to be able to make quantitative statements about the false alarm behavior of flame detectors. Even though absolute data are not yet possible at the present time, I am of the opinion that even those test methods are extremely valuable which permit only a comparative evaluation of flame detectors relative to one another. In particular, supplementing tests of engineering reliability, these comparative tests could be built into a test program for radiation detectors.

As fire alarm manufacturers who also carry flame detectors in their sales program, we have given thought to this topic now for a number of years. It is probably unnecessary to emphasize that the manufacturers must have a vital interest 
in assuring a high level of quality by means of appropriate and practical test standards if the conditions are to be created which will permit fire detectors, and in this case. flame detectors, to receive the confidence which they merit.

A flame detector possesses in general at least one light-sensitive detection element with a specific spectral sensitivity. Among the models being marketed at the present time we find both those which respond principally to the infrared component of the flame spectrum and also those which respond to the visible or ultraviolet portion. Their behavior in response to interference is correspondingly different. Thus, e.g., a detector using lead sulfide as the infrared sensitive sensor is most markedly disturbed by heating radiators while it does not react to ultraviolet sources of interference. Further, almost all modern flame detectors utilize the flame's characteristic of flickering in a specific frequency range. Here, too, there exists a possibility of deception whenever the source of interference displays similar intensity variations.

Because of the already-mentioned lack of information needed for an exact calculation we have taken the empirical path and in so doing have been interested not so much in the question as to what potential interference sources exist as in the question as to what sort of interference factors produce the most sensitive reaction in currently familiar detectors. The evaluation procedure which I am reporting on here makes it possible, in the case of each newly developed detector type, to take into account special interference sources - i.e., to include the latter in the evaluation process. 
I think it is logical to first explain the method itself. Subsequently, I will introduce to you the measuring apparatus specially developed for this purpose and will discuss practical examples and measurement results.

In the following discussion it is advantageous to look upon the detector being tested as a "black box," i.e., to assume in other words that we know nothing about its physical and electrical properties. Our sole assumption is that we are dealing with a radiation detector which is equipped with sensors which correspond to the present state of engineering knowledge. In this way one facilitates the practical application of the procedure, i.e., the tester requires no profound knowledge of the theory and working principle of the test sample.

In the first part of the test procedure an attempt is made to alarm the detector by radiation from well-defined sources of interference. The nature of the interferences has been selected as follows on the basis of existing experience with present-day flame detectors. A heating plate for the simulation of infrared interference sources, an incandescent lamp and a tube of luminous material for the simulation of artificial visible light sources and a gas discharge tube for simulating UV radiators. In order to include the alreadymentioned flame flickering in the deception testing, the intensity of the interfering radiator is varied periodically in the range 5-20 $\mathrm{Hz}$. For each of the individual sources of interference the response sensitivity is determined experimentally insofar as possible by variation of the distance from source to detector with the frequency of the intensity variations being so selected that the sensitivity is greatest. The thus obtained distance values are recorded and evaluated as explained later on. 
It is the purpose of these measurements to discover the sort of interference sources to which the detector most sensitively responds. Subsequently the fire parameter sensitivity of the test specimen is determined with the aid of $a$ test flame, again employing distance as a measure of sensitivity. In this measurement, too, the distance to the radiation source is varied until the detector responds. All the measurements thus obtained are tabulated, as shown in table 1 .

Table 1

Type of Radiation

Interference

Heating plate

Incandescent lamp

Fluorescent light source

UV lamp

Test flame
Distance Between

Detector and Radiator

$\mathrm{d}_{\mathrm{S}} \mathrm{l}$

$\mathrm{d}_{\mathrm{S}}{ }^{2}$

$\mathrm{d}_{\mathrm{S}}{ }^{3}$

$\mathrm{d}_{\mathrm{S}}{ }^{4}$

$d_{F}$

$$
\begin{gathered}
\frac{k}{d_{F}: d_{S 1}} \\
d_{F}: d_{S 2} \\
d_{F}: d_{S 3} \\
d_{F}: d_{S 4}
\end{gathered}
$$

In the first column there is listed the type of radiation and in the second the distances $d_{F}$ and $d_{S}$ found to be necessary to produce an alarm. In the third column we find the ratio of distance values $k=d_{F}: d_{S}$ which we take as a measure of the test specimen's discrimination capability. The greater the computed k-value, the less the effect of the interfering source involved upon the detector. Naturally, the absolute value of this ratio depends markedly upon the dimensioning of the interfering source, i.e., upon the intensity of its emission but as has already been mentioned this procedure does not aim at obtaining absolute statements but aims rather at being able to compare flame detectors with one another 
relative to their susceptibility to interference. However, for this purpose it suffices to hold constant the interference sources, once they have been chosen, and the test fire. The fulfillment of these conditions was the task of the test apparatus which we developed and which I would like now to discuss in more detail.

The four interference sources selected are placed in a common housing and can be switched on and off at will. Figure 1 shows a schematic representation of the apparatus. The interfering radiation emerges from the sketched openings and is periodically chopped (i.e., turned on and off) by a rotating disk. The frequency can be easily varied and kept constant by controlling the revolutions-per-minute. Figure 2 shows the total apparatus with a detector in testing position. First, the distance is chosen to be of such a size that the detector still does not respond. The interference source is always located perpendicularly below the test specimen. Then the detector is slowly brought closer to the apparatus until an alarm is triggered. By repeatedly setting back the alarm and correcting the distance as well as the variation of the chopper frequency it is possible to determine the measurement d with adequate precision for the interference source selected. The same procedure is repeated for the other interference sources. For measuring the effective fire parameter sensitivity, an alcohol flame was chosen as the test fire. A cylindrical metal vessel having a diameter small in comparison with its height is filled about three-fourths with alcohol and then ignited. In this way it is possible to create a well-reproducible flame which burns with sufficient constancy for a fairly long time.

The measurement procedure described has been used at our establishment for some time for the comparison of radiation 
detectors so that we already have a certain degree of experience at our disposal. I should like to briefly present to you some of these results.

The models investigated consist of products of diversified provenance. I am sure that you will understand our not stating any model designations, from which it would be possible to infer the identity of the manufacturer. We merely indicate which sensor is being employed, i.e., in what spectral sensitivity range it is operating. As may be seen in table 2, in addition to data regarding flame sensitivity the table also contains information about the false alarm deception behavior to be expected. Hence one can also speak of this as a sort of suitability table for it furnishes the user with a means of selecting the detector having the greatest resistance to interference, assuming the interfering influences to be known or predictable.

The results existing hitherto clearly show that comparisons carried out in accordance with previously conventional practice (i.e., on the basis of fire parameter sensitivity alone) can easily be misleading. Alarms having the greatest flame sensitivity are very often also most susceptible to interference factors. But this is not brought out during alarm comparisons in simple fire experiments, which cover only the response time of the detection devices.

However, today in engineering circles it is undisputed that the main problem of fire alarm installation is not that of increasing the sensitivity of the detectors but rather reduction of their susceptibility to deception. Therefore we consider extremely valuable any means which helps us to recognize and to exclude risk of deception alarms. It is in this sense that I ask you to look upon the work described 
here as a contribution to the problem of combating deception alarms, which in the case of flame detectors are of especially frequent occurrence. We believe that with our method, at least up until the time when more reliable information exists, we have at our disposal a valid means of evaluating flame detectors. 


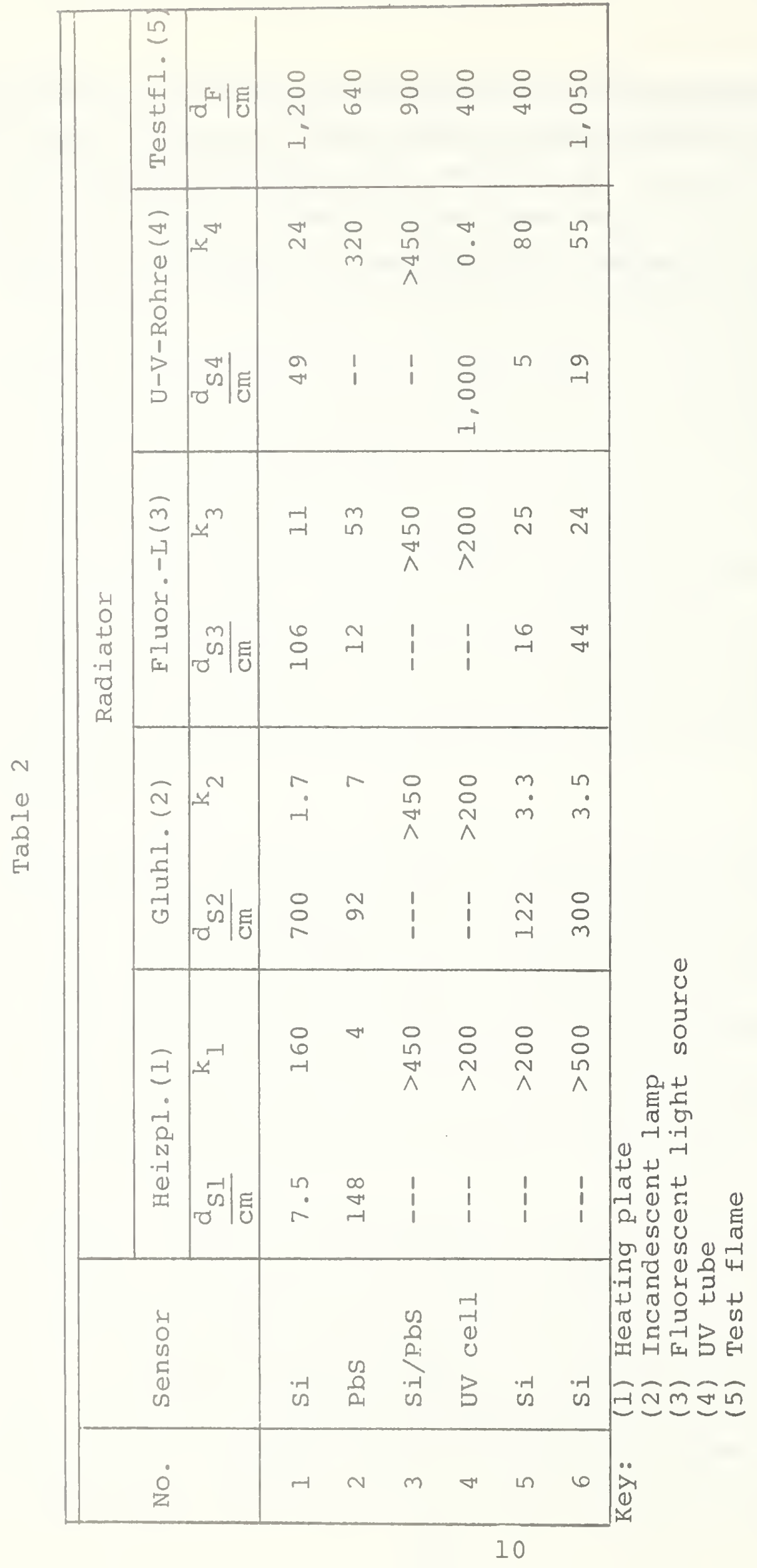



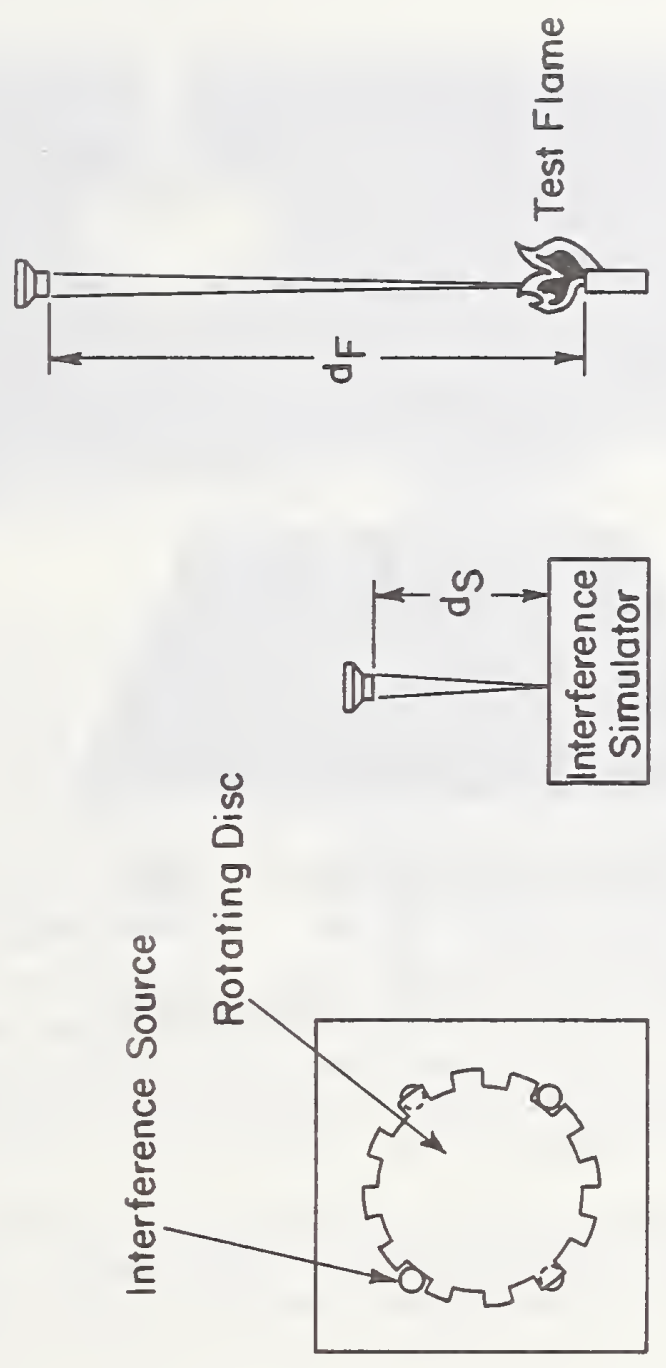


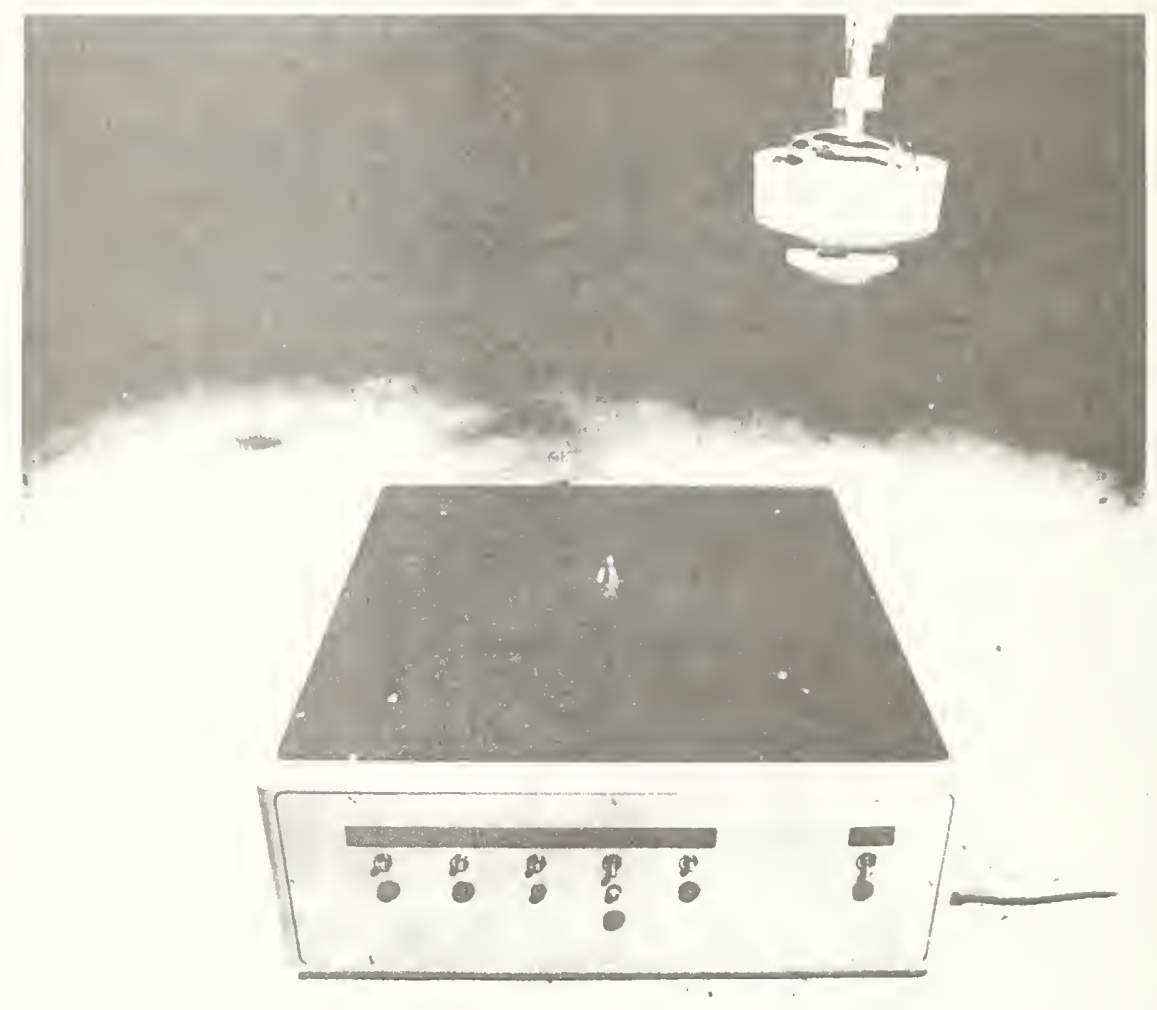

Figure 2. Test Apparatus with

Detector in Testing Position. 
NBS. I14A (REV.7.73)

\begin{tabular}{|c|c|c|c|}
\hline $\begin{array}{l}\text { U.S. DEPT. OF COMM. } \\
\text { BIBLIOGRAPHIC DATA } \\
\text { SHEET }\end{array}$ & $\begin{array}{l}\text { 1. PUIBI.ICATION OR RIPORT NO. } \\
\text { NBSIR 75- } 956\end{array}$ & $\begin{array}{l}\text { 2. (iov't Accession } \\
\text { No. }\end{array}$ & 3. Recipient's Accession No. \\
\hline \multicolumn{3}{|l|}{ 4. TITLE AND SUBTITLE } & 5. Publication Date \\
\hline \multirow{2}{*}{\multicolumn{3}{|c|}{$\begin{array}{l}\text { An Interference Simulator for Quantitative } \\
\text { Determination of the Susceptibility of Flame } \\
\text { Detectors to False Alarm }\end{array}$}} & November 1975 \\
\hline & & & 6. Performing Organization Code \\
\hline \multicolumn{3}{|c|}{$\begin{array}{l}\text { 7. AUTHOR(S) } \\
\text { A. Scheidweiler }\end{array}$} & 8. Performing Organ. Report No. \\
\hline \multicolumn{3}{|c|}{ 9. PERFORMING ORGANIZATION NAME AND ADDRESS } & 10. Project/Task/Work Unit No. \\
\hline \multicolumn{3}{|c|}{$\begin{array}{l}\text { NATIONAL BUREAU OF STANDARDS } \\
\text { DEPARTMENT OF COMMERCE } \\
\text { WASHINGTON, D.C. } 20234\end{array}$} & $\frac{4928677}{11 . \text { Contract/Grant No. }}$ \\
\hline \multirow{2}{*}{\multicolumn{3}{|c|}{ 12. Sponsoring Organization Name and Complete Address (Street, City, State, ZIP) }} & $\begin{array}{l}\text { 13. Type of Report \& Period } \\
\text { Covered } \\
\text { Final Report }\end{array}$ \\
\hline & & & 14. Sponsoring Agency Code \\
\hline
\end{tabular}

15. SUPPLEMENTARY NOTES

16. ABSTRACT (A 200-word or less factual summary of most significant information. If document includes a significant bibliography or literature survey, mention it here.)

All fire detectors are susceptible to false alarms, i.e., responding to fire-like conditions when no fire is present. Of all the known fire detectors, flame detectors are probably the most false alarm prone of any of the fire detectors, primarily because these detectors are subjected to more environmental influences resembling the detectors' operating mode than any other fire detector.

In this paper, the author describes an investigation into the susceptibility of flame detectors to false alarms. The author describes a test apparatus, constructed and used by his firm, to evaluate the susceptibility of currently-available flame detectors to false alarms. In addition, the apparatus can be used to evaluate prototype flame detectors.

The data developed indicates the false alarm susceptibility of each type of flame sensor. The data also provides a means of selecting a flame detector having the greatest resistance to known or predictable pseudo-fire sources.

17. KEY WORDS (six to twelve entries; alphabetical order; capitalize only the first letter of the first key word unless a proper. name; separated by semicolons) Flase alarms; false alarm simulator; fire detection; fire detector; flame detection; flame detector.

18. AVAILABILITY

$\square$ For Official Distribution. Do Not Release to NTIS

$\square$ Order From Sup. of Doc., U.S. Government Printing Office Washington, D.C. 20402, SD Cat. No. C13

$\square$ Order From National Technical Information Service (NTIS) Springfield, Virginia 22151

\begin{tabular}{|l|c|}
\hline $\begin{array}{l}\text { 19. SECURITY CLASS } \\
\text { (THIS REPURT) } \\
\text { UNCL ASSIFIED }\end{array}$ & 21. NO. OF PAGES \\
\hline $\begin{array}{l}\text { 20. SECURITY CLASS } \\
\text { (THIS PAGE) } \\
\text { UNCLASSIFIED }\end{array}$ & $\begin{array}{l}\text { 22. Price } \\
\$ 3.25\end{array}$ \\
\hline
\end{tabular}






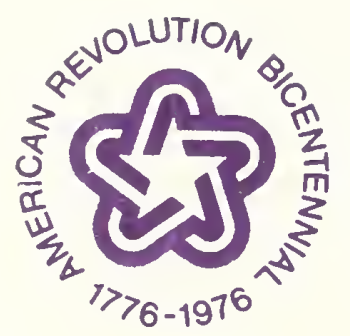

